\title{
Altered Responses to Cold Environment in Urocortin 1 and Corticotropin-Releasing Factor Deficient Mice
}

\author{
Bayan Chaker, ${ }^{1}$ Tareq A. Samra, ${ }^{2}$ Nabanita S. Datta, ${ }^{1}$ and Abdul B. Abou-Samra ${ }^{1,2}$ \\ ${ }^{1}$ Endocrine Division, Department of Medicine, Wayne State University School of Medicine, Detroit, MI 48201, USA \\ ${ }^{2}$ Department of Medicine, Hamad Medical Corporation, Doha, Qatar
}

Correspondence should be addressed to Abdul B. Abou-Samra; absamra@gmail.com

Received 10 December 2012; Revised 10 April 2013; Accepted 23 April 2013

Academic Editor: Sulayman D. Dib-Hajj

Copyright (c) 2013 Bayan Chaker et al. This is an open access article distributed under the Creative Commons Attribution License, which permits unrestricted use, distribution, and reproduction in any medium, provided the original work is properly cited.

\begin{abstract}
We examined core body temperature (CBT) of urocortin 1 (UCN1) and corticotropin releasing factor (CRF) knockout (KO) mice exposed to $4^{\circ} \mathrm{C}$ for $2 \mathrm{~h}$. UCN1KO mice showed higher average CBT during cold exposure as compared to WT. The CBT of male and female WT mice dropped significantly to $34.1 \pm 2.4$ and $34.9 \pm 3.1 \mathrm{C}$ at $4^{\circ} \mathrm{C}$, respectively. In contrast, the CBT of male and female $\mathrm{UCN} 1 \mathrm{KO}$ mice dropped only slightly after $2 \mathrm{~h}$ at $4^{\circ} \mathrm{C}$ to $36.8 \pm 0.7$ and $38.1 \pm 0.5 \mathrm{C}$, respectively. WT female and male $\mathrm{UCN1KO}$ mice showed significant acclimatization to cold; however, female UCN1KO mice did not show such a significant acclimatization. CRFKO mice showed a dramatic decline in CBT from $38.2 \pm 0.4$ at $22^{\circ} \mathrm{C}$ to $26.1 \pm 9.8$ at $4^{\circ} \mathrm{C}$ for $2 \mathrm{~h}$. The CRF/UCN1 double KO $(\mathrm{dKO})$ mice dropped their CBT to $32.5 \pm 4.0$ after $2 \mathrm{~h}$ exposure to $4^{\circ} \mathrm{C}$. Dexamethasone treatment prevented the decline in CBT of the CRFKO and the dKO mice. Taken together, the data suggest a novel role for UCN1 in thermoregulation. The role of CRF is likely secondary to adrenal glucocorticoids, which have an important regulatory role on carbohydrate, fat, and protein metabolism.
\end{abstract}

\section{Introduction}

Corticotropin releasing factor (CRF) [1] plays an essential role in the physiological regulation of the hypothalamicpituitary-adrenal (HPA) as CRF knockout (KO) mice have low concentrations of corticosterone and decreased response to stress [2]. CRF is also found in several regions of the central nervous system (CNS) where it functions as a neurotransmitter and regulates several aspects of behavior particularly in response to stressful stimuli [3].

The urocortins, UCN1 [4], UCN2 [5], and UCN3 [6], are a family of peptides, which were discovered by their sequence homology to CRF, sauvagine [7], and urotensin 1 [8]. These peptides bind and activate the CRF receptors, CRFR1 [9] and CRFR2 [10], with different affinities and potencies. CRF binds to CRFR1 with a higher affinity than to CRFR2, whereas UCN1, sauvagine, and urotensin 1 interact with both receptors with a relatively similar affinity [10]. In contrast, UCN2 and UCN3 have higher affinity for CRFR2 than for CRFR1 $[5,6]$. Therefore, the actions of UCN1 can be mediated by both CRF receptors [11]. In this regard, it has been shown that UCN1 mRNA levels are upregulated in the Edinger-Westphal (EW) nucleus of mice following stress exposure [12]. UCN1-deficient mice were shown to have a normal corticosterone response to acute immobilization stress $[13,14]$; however, they showed anxiety-like behavior and impaired inner ear physiology [13]. UCN1KO mice were also shown to have decreased corticosterone response to cold and impaired adaptation to repeated constraints [15].

A role for UCN1 in thermoregulation has been suggested from the finding that intracerebroventricular injection of UCN1 in rats significantly increased colonic temperature [16] and that a cyclooxygenase inhibitor reduced this effect of UCN1 [17].

In this study, we assessed the hypothesis that UCN1 may be important for the maintenance of core body temperature during exposure to cold environment and examined the acclimatization of the core body temperature to a $2 \mathrm{~h}$ cold exposure of mice deficient in UCN1, CRF, or both.

\section{Materials and Methods}

2.1. Animals. The UCN1KO mice, in the $\mathrm{C} 57 \mathrm{BL} / 6$ background, were described by us previously [15]. The CRFKO 
TABLE 1: Inner body temperature of UCN1KO mice at $4^{\circ} \mathrm{C}$ is higher than that of WT mice: statistical comparison of average rectal temperatures, taken every 10 min during $2 \mathrm{~h}$ ( 9 to 13 measurements for each mouse, $n=6-7$ animals in each group) of exposure to $4^{\circ} \mathrm{C}$. Statistical analysis was made using ANOVA followed by Student's $t$-test.

\begin{tabular}{lcccc}
\hline Sex & Genotype & $\begin{array}{c}{ }^{*} \text { Average rectal } \\
\text { temperatures at } 4{ }^{\circ} \mathrm{C}\end{array}$ & $n$ & $P$ values \\
\hline \multirow{2}{*}{ Males } & WT & $36.5 \pm 1.4$ & 7 & $<0.01$ \\
& UCN1KO & $37.1 \pm 1.0$ & 7 & \\
\hline \multirow{2}{*}{ Females } & WT & $36.8 \pm 1.1$ & 6 & $<0.001$ \\
& UCN1KO & $37.9 \pm 0.4$ & 6 & \\
\hline
\end{tabular}

TABLE 2: UCN1KO and WT mice have similar body weights: statistical analysis was done using ANOVA followed by Student's $t$ test.

\begin{tabular}{lcccc}
\hline Sex & Genotype & $\begin{array}{c}\text { Body weight (grams) } \\
\text { means } \pm \text { SEM }\end{array}$ & $(n)$ & $P$ values \\
\hline \multirow{2}{*}{ Males } & WT & $24.8 \pm 0.41$ & 29 & 0.157 \\
& UCN1KO & $26.0 \pm 0.67$ & 33 & \\
\hline \multirow{2}{*}{ Females } & WT & $21.4 \pm 0.40$ & 24 & 0.214 \\
& UCN1KO & $20.7 \pm 0.35$ & 30 & \\
\hline
\end{tabular}

mice, developed by Muglia et al. [2] and backcrossed into C57BL/6 background for more than 6 generations, were obtained from Dr. J. Majzoub, (Children's Hospital, Boston MA, USA). CRF/UCN1 double KO (dKO) mice were developed by mating male CRFKO mice with female UCN1 KO mice. Genotyping was performed by Transnetyx (Cordova, TN, USA) using mouse tissue samples analyzed by real-time PCR. The PCR primers were designed for the CRF and UCN1 loci as in Table 5.

Mice were housed in polycarbonate micro isolators with filter tops at a controlled environment of $70-74^{\circ} \mathrm{F}$ ambient temperature, $40-60 \%$ humidity, and $12 \mathrm{~h} / 12 \mathrm{~h}$ light-dark cycles. Regular rodent chow, LabDiet number 5001, and water were given ad libitum. Depending on the litter size, mice were housed in either small cages which had a maximum of 4 mice per cage or large cages which had a maximum of 10 mice per cage. During experiments, mice were housed individually in small cages. The study protocol was approved by the institutional animal care and use committee (Animal Welfare Assurance number A 3310-01).

2.2. Body Weight Measurements. Mice body weights were measured using an electronic scale (Mettler PE400) with a sensitivity of 0.01 grams.

2.3. Cold Stress Experiments. Mice, 8-16 weeks old, were individually housed and exposed to $4^{\circ} \mathrm{C}$ or $22^{\circ} \mathrm{C}$ for 2 hours in the absence of food and water. Internal body temperature was measured using an electronic rectal probe (TW2-193, Braintree Scientific) every ten minutes for two hours. The mouse was restrained by the tail wrap method in which the tail is transferred from the thumb and forefinger to the fourth
TABLE 3: Female UCN1KO mice do not acclimatize to cold environment. Statistical comparison of average rectal temperatures, taken every 10 min during $2 \mathrm{~h}$ (10 to 13 measurements for each mouse, 3 to 8 animals in each group) in mice exposed 2 times to $4^{\circ} \mathrm{C}$. The second time was performed 3 days after the first attempt. Statistical analysis was made using ANOVA followed by Student's $t$-test.

\begin{tabular}{|c|c|c|c|c|c|}
\hline Genotype & Sex & $\begin{array}{l}\text { Attempt } \\
\text { number }\end{array}$ & $\begin{array}{l}\text { Rectal temperature } \\
\left({ }^{\circ} \mathrm{C}\right) \text { means } \pm S D\end{array}$ & $(n)$ & $P$ values ${ }^{(a)}$ \\
\hline \multirow{4}{*}{ WT } & \multirow{2}{*}{ Males } & 1st & $36.9 \pm 0.8$ & 7 & \multirow{2}{*}{$<0.001$} \\
\hline & & $2 \mathrm{nd}$ & $37.4 \pm 0.6$ & 7 & \\
\hline & \multirow{2}{*}{ Females } & $1 s t$ & $37.3 \pm 0.4$ & 7 & \multirow{2}{*}{$<0.001$} \\
\hline & & 2nd & $38.0 \pm 0.4$ & 3 & \\
\hline \multirow{4}{*}{ UCN1KO } & Males & $1 s t$ & $37.3 \pm 0.7$ & 6 & \multirow{2}{*}{$<0.05$} \\
\hline & & 2 nd & $37.8 \pm 0.6$ & 3 & \\
\hline & \multirow{2}{*}{ Females } & 1st & $37.8 \pm 0.5$ & 8 & \multirow{2}{*}{ NS } \\
\hline & & $2 \mathrm{nd}$ & $37.6 \pm 0.5$ & 6 & \\
\hline
\end{tabular}

and fifth fingers. The tail presses into the palm of the hand and then the thumb and forefinger grasp a scuff of skin located in the occiput of the animal. The rectal probe was lubricated by olive oil and then inserted $1 \mathrm{~cm}$ into the mouses rectum for about 5 seconds. Temperatures were measured at 10minute intervals during the 120 -minute period. A total of 13 temperature readings were taken per mouse per experiment. Experiments were performed between 9 am and $5 \mathrm{pm}$.

2.4. Dexamethasone Treatment Experiment. CRFKO and dKO mice were given daily intramuscular (IM) dexamethasone injections for three consecutive days. Each dexamethasone injection consisted of $1 \mu \mathrm{g}$ of dexamethasone dissolved in $0.1 \mathrm{~mL}$ of $0.9 \%$ saline solution. On the fourth day (the day following the last injection), mice were exposed to $4^{\circ} \mathrm{C}$ for 2 hours, and the internal body temperature was recorded at 10 minute intervals using the same electronic rectal probe mentioned earlier.

2.5. Cold Acclimatization Experiments. To study the effects of cold environment on internal body temperature, male and female UCN1KO and WT littermate mice, 8-12 weeks old, were exposed for a second time (3 days after the first exposure) to $4^{\circ} \mathrm{C}$ for 2 hours; the internal body temperature was recorded at 10-minute intervals using the same method described above.

2.6. Tissue Homogenization. Skeletal muscle, subcutaneous adipose (SQ fat), visceral adipose ( $\mathrm{v}$ fat), brown adipose (BAT), kidney, heart, and liver tissues were isolated from WT and UCN1KO male and female 8-12 weeks old C57BL/6 mice. Tissue samples, $100-200 \mathrm{mg}$, were placed in $400 \mu \mathrm{L}$ of Trizol reagent (Invitrogen) on ice. Tissue samples were homogenized using three 5-minute cycles at max speed of a Bullet Blender with stainless steel beads (BBX24B, Next Advance, Averill Park, NY, USA) at $4^{\circ} \mathrm{C}$. Trizol reagent $(600 \mu \mathrm{L})$ was added to the homogenates. The samples were then centrifuged at $3000 \mathrm{~g}$ for 5 minutes at $4^{\circ} \mathrm{C}$. Supernatants 
TABLE 4: Expression levels of transcripts measured by real-time polymerase chain reaction (RT-PCR) from total RNA prepared from brown adipose tissues (BAT), skeletal muscles, kidney, subcutaneous fat (SQ fat), liver, and heart. The data are expressed as means \pm SEM. $P$ values of UCN1 KO versus WT were calculated using Student's $t$-test. BAT: brown adipose tissue; UCP1: uncoupling protein 1; THR- $\alpha$ : thyroid hormone receptor- $\alpha$ subunit; THR- $\beta$ : thyroid hormone receptor- $\beta$ subunit; AdpR1: adiponectin receptor 1; AdpR2: adiponectin receptor 2; CRFR2: corticotropin-releasing hormone receptor 2.

\begin{tabular}{|c|c|c|c|c|c|c|}
\hline Gene & Tissue & Sex & Genotype & RQ & $(n)$ & $P$ values \\
\hline \multirow{4}{*}{ UCP1 } & \multirow{4}{*}{ BAT } & \multirow{2}{*}{ Females } & WT & $0.74 \pm 0.38$ & 6 & \multirow{2}{*}{0.493} \\
\hline & & & UCN1KO & $0.44 \pm 0.23$ & 8 & \\
\hline & & \multirow{2}{*}{ Males } & WT & $3.10 \pm 1.53$ & 9 & \multirow{2}{*}{0.802} \\
\hline & & & UCN1KO & $2.61 \pm 1.11$ & 9 & \\
\hline \multirow{4}{*}{ THR- $\alpha$} & \multirow{4}{*}{ Skeletal muscle } & \multirow{2}{*}{ Females } & WT & $2.22 \pm 0.93$ & 6 & \multirow{2}{*}{0.731} \\
\hline & & & UCN1KO & $1.74 \pm 0.96$ & 7 & \\
\hline & & \multirow{2}{*}{ Males } & WT & $2.40 \pm 1.30$ & 8 & \multirow{2}{*}{0.959} \\
\hline & & & UCN1KO & $2.49 \pm 0.94$ & 6 & \\
\hline \multirow{4}{*}{ THR- $\beta$} & \multirow{4}{*}{ Kidney } & \multirow{2}{*}{ Females } & WT & $0.42 \pm 0.15$ & 6 & \multirow{2}{*}{0.864} \\
\hline & & & UCN1KO & $0.39 \pm 0.11$ & 8 & \\
\hline & & \multirow{2}{*}{ Males } & WT & $2.98 \pm 0.86$ & 9 & \multirow{2}{*}{0.884} \\
\hline & & & UCN1KO & $3.19 \pm 1.16$ & 7 & \\
\hline \multirow{4}{*}{ Adiponectin } & \multirow{4}{*}{ SQ fat } & \multirow{2}{*}{ Females } & WT & $1.25 \pm 0.23$ & 6 & \multirow{2}{*}{0.547} \\
\hline & & & UCN1KO & $1.48 \pm 0.28$ & 6 & \\
\hline & & \multirow{2}{*}{ Males } & WT & $1.00 \pm 0.30$ & 8 & \multirow{2}{*}{0.273} \\
\hline & & & UCN1KO & $1.78 \pm 0.64$ & 7 & \\
\hline \multirow{4}{*}{ AdpR1 } & \multirow{4}{*}{ Skeletal muscle } & \multirow{2}{*}{ Females } & WT & $2.00 \pm 0.29$ & 6 & \multirow{2}{*}{0.014} \\
\hline & & & UCN1KO & $1.09 \pm 0.16$ & 8 & \\
\hline & & \multirow{2}{*}{ Males } & WT & $0.56 \pm 0.13$ & 9 & \multirow{2}{*}{0.905} \\
\hline & & & UCN1KO & $0.60 \pm 0.28$ & 7 & \\
\hline \multirow{4}{*}{ AdpR2 } & & Females & WT & $0.58 \pm 0.10$ & 6 & 0.176 \\
\hline & Liver & rentales & UCN1KO & $0.37 \pm 0.10$ & 8 & $0.1 / 0$ \\
\hline & LIVET & Males & WT & $0.67 \pm 0.12$ & 9 & 0.175 \\
\hline & & Niaies & UCN1KO & $1.46 \pm 0.54$ & 9 & $0.17 \mathrm{~J}$ \\
\hline & & Females & WT & $0.28 \pm 0.15$ & 6 & 0.368 \\
\hline CRFR2 & Heart & & UCN1KO & $0.96 \pm 0.65$ & 7 & \\
\hline СКгК & neart & Males & WT & $4.04 \pm 1.21$ & 8 & 0.319 \\
\hline & & Males & UCN1KO & $6.14 \pm 1.70$ & 6 & 0.319 \\
\hline
\end{tabular}

TABLE 5

\begin{tabular}{llcr}
\hline Gene locus & Forward primer & Reverse primer & Size of PCR product \\
\hline CRF WT & GCTCAGCAAGCTCACAGCAA & GAGCTTACACATTTCGTCC & $400 \mathrm{bp}$ \\
CRF KO & ATCGCCTTCTTGACGACTTC & GAGCTTACACATTTCGTCC & $600 \mathrm{bp}$ \\
UCN1 WT & GAGGGGACGCGCTACGCTCC & GTCCGAGCTAGCTCCAGCAG & $400 \mathrm{bp}$ \\
UCN1 KO & GTCCGAGCTAGCTCCAGCAG & GCGAATGGGCTGACCGCTTC & $900 \mathrm{bp}$ \\
\hline
\end{tabular}

TABLE 6

\begin{tabular}{lcc}
\hline Gene & Forward primer & Reverse primer \\
\hline UCP1 & GAAGGATTGCCGAACTG & CAATGAACACTGCCACAC \\
THR- $\alpha$ & GTCAGACCCAGAGGAGAACAG & CACAAGTGATACAGCGGTAGTG \\
THR- $\beta$ & CAACCAGTGCCAGGAATGTC & CGCCTCTTCTCACGGTTC \\
CRFR2 & CTGCTTCCAGTGCTCCAGGTG & CTACTAGGGCTCCGGGTGC \\
Adiponectin & CACCAAAAGGGCTCAGGATGC & CTGCCATCACGGCCTGGTGTG \\
Adiponectin receptor 1 & GCACAGTGGGACCGGTTTGC & CACCGTGGTGGCCTTGAC \\
Adiponectin receptor 2 & GTCAGAGCAGGAGTGTTCGTG & GTGGCAGCCTTCAGGAAC \\
$\beta$-Sctin & GCCTTCCTTCTTGGGTATG & GATCTTGATCTTCATGGTGC \\
\hline
\end{tabular}


were isolated and placed in fresh $1.5 \mathrm{~mL}$ RNAase/DNAasefree $1.5 \mathrm{~mL}$ microcentrifuge tubes and stored at $-80^{\circ} \mathrm{C}$.

2.7. RT-PCR. Homogenized samples were thawed on ice $\left(4^{\circ} \mathrm{C}\right)$ and RNA extraction was continued as per the manufacturer's protocol (Invitrogen). cDNA synthesis was performed using a reverse transcription system kit (Promega). Real-time PCR was performed using a 40-cycle PCR protocol using SYBR green reagent (SA Biosciences). Data were reported as relative quantity (RQ) of the amount of mRNA of interest corrected by the amount of $\beta$-actin mRNA in the same sample (see Table 4).

Specific RT-PCR primers were designed for each of the genes (see Table 6).

2.8. Statistical Analysis. The significance of change between groups, that is, between two groups, was determined using Student's $t$-test. Moreover, when 3 or more groups are compared, one-way analysis of variance (ANOVA) was first used. Statistical analyses were performed on SPSS. Means and standard deviations (SD) are reported in the tables, and means and standard errors of the means (SEM) are shown in the figures.

\section{Results and Discussion}

3.1. Rectal Temperatures at $22^{\circ} \mathrm{C}$ and $4^{\circ} \mathrm{C}$ of Wild Type and UCN1KO Mice. The inner body temperature measured every $10 \mathrm{~min}$ in mice kept at $22^{\circ} \mathrm{C}$ for $2 \mathrm{~h}$ was stable in all the mice, regardless of genotype or sex, and was in the range of 38.1 to 38.6 (Figure 1, top panel). Male and female WT mice, kept at $4^{\circ} \mathrm{C}$ for $2 \mathrm{~h}$, dropped their inner body temperature to $34.1 \pm 2.4^{\circ} \mathrm{C}(P<0.001)$ and $34.9 \pm 3.1^{\circ} \mathrm{C}(P<0.001)$ at $120 \mathrm{~min}$, respectively, (Figure 1, lower panel). In contrast, the inner body temperature of male and female UCN1KO mice kept at $4^{\circ} \mathrm{C}$ for $2 \mathrm{~h}$ decreased only to $36.8 \pm 0.7^{\circ} \mathrm{C}(P<0.01)$ and $38.1 \pm 0.5^{\circ} \mathrm{C}(P<0.05)$, respectively (Figure 1$)$. We also compared the averages of all values taken during the $120 \mathrm{~min}$ at $4^{\circ} \mathrm{C}$ between WT and UCN1KO mice (Table 1). The inner body temperature of UCN1KO mice was significantly higher than that of WT mice in both males and females (Table 1).

The thermoregulatory response to cold is a complex biological process that involves multiple neuroendocrine pathways $[18,19]$. UCN1 is an important neuropeptide, which plays multiple roles in animal physiology particularly in the adaptive phase to stress [20]. UCN1KO mice were reported to have a sensory hearing loss with normal corticosterone level and normal adrenal response to acute restraint stress $[13,14]$, impaired acclimatization of corticosterone response to repeated constraints, and impaired response to cold stress [15]. Our data showing that UCN1KO mice exposed to $2 \mathrm{~h}$ cold environment $\left(4^{\circ} \mathrm{C}\right)$ had a higher average core body temperature than sex- and aged-matched WT littermates suggest an important role for UCN1 in thermoregulation. Furthermore, the ability of UCN1KO mice to tolerate $4^{\circ} \mathrm{C}$ environment may explain our previous finding of impaired corticosterone response to cold stress in these mice. The $2 \mathrm{~h}$ cold exposure of the UCN1KO mice may not represent a

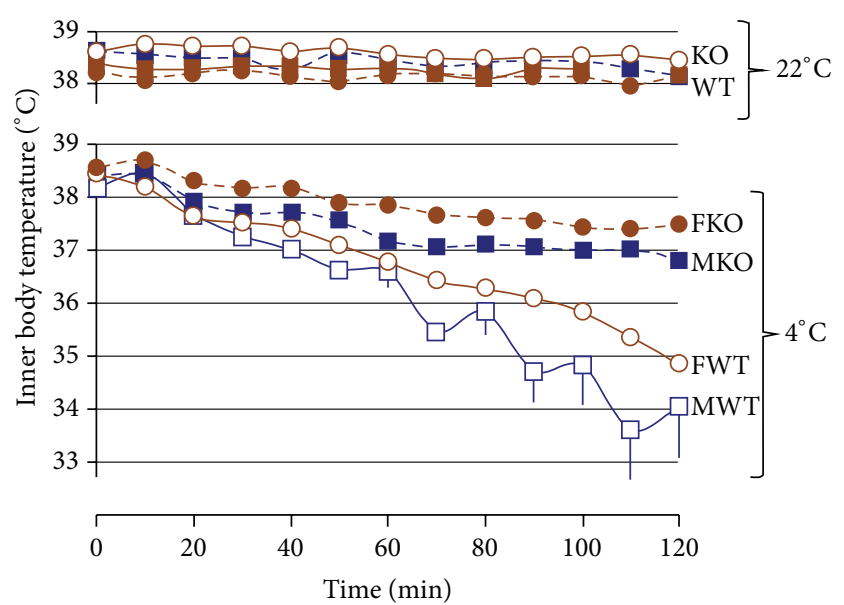

FIGURE 1: Rectal temperatures in wild type (WT) and UCN1 KO mice kept for 2 hours at room temperature (RT, $22^{\circ} \mathrm{C}$ ) or at $4^{\circ} \mathrm{C}$. Rectal temperature was measured with an electronic probe every $10 \mathrm{~min}$. The data are means $\pm \operatorname{SEM}\left(n=3\right.$ at $22^{\circ} \mathrm{C}$ and $n=6$ at $4^{\circ} \mathrm{C}$ ) and are recorded from female WT (FWT, empty circles, solid lines), female UCN1 KO (FKO, filled circles, dotted lines), male WT (MWT, empty squares, solid lines), and male UCN1KO (MKO, filled squares, dotted lines).

sufficient stress to increase the HPA activity, as inner body temperature does not decline as readily as WT mice.

3.2. Body Weight of Wild Type and UCN1KO Mice. As body size may influence heat loss in the cold, we measured the body weight of the UCN1KO and WT mice. The body weights of WT mice were not different from those of UCN1KO mice: $26.0 \pm 0.7$ versus $24.8 \pm 0.4 \mathrm{gr}$ for males and $20.7 \pm 0.4$ versus $21.4 \pm 0.4 \mathrm{gr}$ for females, respectively (Table 2 ). The data suggest that body weight does not contribute in the difference in core body temperatures observed in WT or UCN1KO mice kept at room temperature or at $4^{\circ} \mathrm{C}$.

3.3. Rectal Temperatures at $22^{\circ} \mathrm{C}$ and $4^{\circ} \mathrm{C}$ of CRFKO and $U C N 1 / C R F$ dKO Mice. To investigate the role of CRF in temperature regulation, we recorded the internal body temperature of female CRFKO and UCN1/CRF dKO mice at $22^{\circ} \mathrm{C}$ and $4^{\circ} \mathrm{C}$ for $2 \mathrm{~h}$. The internal body temperatures of CRFKO and $\mathrm{UCN} 1 / \mathrm{CRF} \mathrm{dKO}$ mice at $22^{\circ} \mathrm{C}$ were stable throughout the 2-hour period $\left(37.8 \pm 0.2\right.$ and $38.1 \pm 0.1^{\circ} \mathrm{C}$, resp.). In contrast, at $4^{\circ} \mathrm{C}$ the inner body temperatures of CRFKO and $\mathrm{UCN1} / \mathrm{CRF}$ dKO mice showed dramatic declines to $26.1 \pm$ $4.9^{\circ} \mathrm{C}(P<0.01)$ and $32.5 \pm 1.8^{\circ} \mathrm{C}(P<0.05)$, respectively (Figure 2).

Since CRF deficiency results in glucocorticoid deficiency [2], we treated CRFKO and CRF/UCN1 dKO mice with dexamethasone for 3 days and assessed their internal body temperature fluctuation at $22^{\circ} \mathrm{C}$ and at $4{ }^{\circ} \mathrm{C}$ on day 4 . Dexamethasone treatment prevented the dramatic decline in internal body temperature in both the CRFKO and the CRF/UCN1 $\mathrm{dKO}$ mice (Figure 2); their average body temperature was not significantly different from mice kept at $22^{\circ} \mathrm{C}$. 


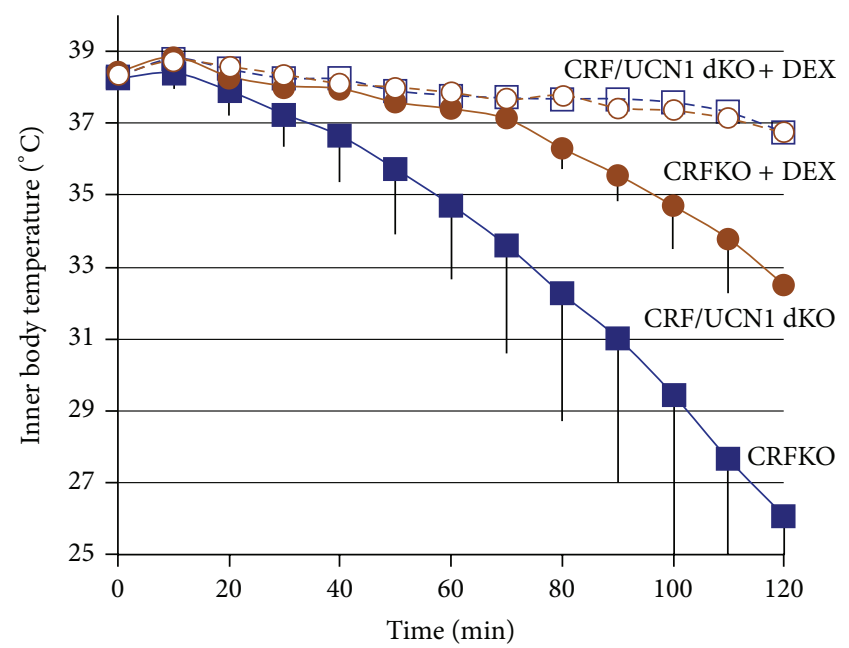

Figure 2: Responses to cold environment $\left(4^{\circ} \mathrm{C}\right)$ in female CRFKO $(n=4)$ and CRF/UCN1 dKO $(n=4)$ mice, $12-16$ weeks old, before and after treatment with $1 \mu \mathrm{g} /$ animal/day for 3 days with dexamethasone (+DEX). Rectal temperature was measured with an electronic probe every $10 \mathrm{~min}$. The data are means \pm SEM.

Several reports have previously shown involvement of the UCNs/CRF peptides in thermoregulation. Intracerebroventricular injection of CRF and UCN1 in rats induced a hyperthermic response, the effects of CRF were mediated by CRFR1, whereas the effects of UCN1 were mediated by CRFR2 [21]. Intraperitoneal injection of CRF and UCN1 reduced oxygen consumption in lean and ob/ob mice [22]. Central administration of a CRF-BP ligand inhibitor in rats elevates rectal and core temperature without accompanying cardiovascular activation [23]. Mice deficient for CRFR2 showed significantly elevated basal brown fat thermogenesis and prolonged adrenergic responses in older mice and decreased respiratory exchange ratio; the latter was normalized with a CRFR1 antagonist [24].

The striking decline in core body temperature of the CRFKO mice can be attributed to either corticosterone deficiency or lack of central effects of CRF. Since the impaired tolerance to cold environment was rescued by dexamethasone treatment, it is likely that the decreased tolerance of the CRFKO mice to cold is primarily secondary to corticosterone deficiency. In this regard, glucocorticoids were reported to protect core body temperature from hypothermia induced by inhalation of a $0^{\circ} \mathrm{C}$ mixture of helium : oxygen $(80: 20)$ and to promote animal survival [25].

The CRF/UCN1 dKO mice had a lower average internal body temperature during the 2-hour cold exposure than their WT littermates but higher temperature than the CRFKO mice; this phenotype suggests different physiological roles for UCN1 and CRF in thermoregulation. Similar to our finding in the CRFKO mice, the impaired tolerance to cold stress of the CRF/UCN1 dKO mice was also reversed by a 3day dexamethasone treatment. This further suggests that the impaired tolerance to cold stress of the $\mathrm{dKO}$ mice, despite being alleviated by the UCN1 deficiency, is primarily due to corticosterone deficiency.
3.4. Acclimatization of Inner Body Temperature to Repeated Exposure to Cold. Because the stress response is an adaptive phenomenon and because UCN1KO mice do not show adaptation to repeated immobilization stress [15], the acclimatization of WT and UCN1KO mice to repeated cold exposure was investigated. Exposure of male and female WT mice and male UCN1KO to $4^{\circ} \mathrm{C}$ for a second time (Table 3 ) showed that the second exposure was less effective in causing a decline in inner body temperature by about $0.5^{\circ} \mathrm{C}$ (Table 3 ). In contrast, the average inner body temperatures of female UCN1KO mice during the first exposure and the second exposure were not different (Table 3 ). This suggests sex difference in the UCN1KO mice acclimatization to cold environment. This contrasts with the lack of acclimatization of the corticosterone response to $15 \mathrm{~min}$ constraint described in both male and female UCN1KO mice [15]. Sexual dimorphism in physiological responses may be secondary to differences in sex hormones and/or in body fat composition.

3.5. Gene Expression. To probe the mechanism of the increased tolerance to cold stress in UCN1KO mice, we measured the steady-state levels of mRNA expression for selected genes thought to be involved in the regulation of thermogenesis and basal metabolic rates in white and brown adipose tissues, muscles, and liver obtained from WT and UCN1KO mice. These genes include the thyroid hormone receptors, which are known to be involved in the thermoregulatory response [26], and the uncoupling protein 1 (UCP1) which was shown to be important in the nonshivering thermoregulatory response [27]. We examined by real-time PCR the mRNA levels of UCP1 in brown adipose tissue (BAT), thyroid hormone receptor- $\alpha$ (THR- $\alpha$ ) in skeletal muscles, thyroid hormone receptor- $\beta$ (THR- $\beta$ ) in kidneys, adiponectin in subcutaneous fat (SQ-fat), adiponectin receptor 1 (AdpR1) in skeletal muscles, adiponectin receptor 2 (AdpR2) in liver, and CRFR2 in the heart. AdpR1 mRNA expression in skeletal muscle was significantly higher in female WT mice compared to UCN1KO mice $(2.00 \pm 0.29$ versus $1.09 \pm 0.16$, resp. $)(P<0.05)$. No other significant difference was detected in the expression of the other genes (Table 3). AdpR1 is known to be involved in physiological functions related to insulin regulation and may have a role in thermoregulation which is yet to be discovered. Malefemale differences in gene expression are not uncommon; the decreased AdpR1 expression in female UCN1KO mice may contribute to sexual dimorphism in physiological responses between male and female mice, such as lack of acclimatization to the cold of the female mice (Table 2).

\section{Conclusion}

Both UCN1 and CRF play important roles in the thermoregulatory response to cold. The role of CRF seems to be secondary to adrenal corticosterone. The role of CRF and glucocorticoid in thermoregulation is not surprising as they have dramatic effects on the metabolism of carbohydrate, fat, and protein; however, our findings suggest a novel role for UCN1 in thermoregulation that has not been previously recognized. 
UCN1 may modulate the central thermoregulatory circuits or may influence basal metabolic rate and/or heat generation, as CRFR1 and CRFR2 are widely distributed in the CNS and in the periphery.

\section{Authors' Contributions}

Bayan Chaker and Tareq A. Samra contributed equally.

\section{Acknowledgments}

The authors would like to acknowledge the assistance of Alemu Fite, Ph.D. and Chandrika Mahalingam, M.S. The work was supported by NIDDK R01DK063211 and start-up funds from Wayne State University School of Medicine to ABAS.

\section{References}

[1] W. Vale, J. Spiess, C. Rivier, and J. Rivier, "Characterization of a 41-residue ovine hypothalamic peptide that stimulates secretion of corticotropin and $\beta$-endorphin," Science, vol. 213, no. 4514, pp. 1394-1397, 1981.

[2] L. Muglia, L. Jacobson, P. Dikkes, and J. A. Majzoub, "Corticotropin-releasing hormone deficiency reveals major fetal but not adult glucocorticoid need," Nature, vol. 373, no. 6513, pp. 427-432, 1995.

[3] T. L. Bale and W. W. Vale, "CRF and CRF receptors: role in stress responsivity and other behaviors," Annual Review of Pharmacology and Toxicology, vol. 44, pp. 525-557, 2004.

[4] J. Vauhan, C. Donaldson, J. Bittencourt et al., "Urocortin, a mammalian neuropeptide related to fish urotensin I and to corticotropin-releasing factor," Nature, vol. 378, no. 6554, pp. 287-292, 1995.

[5] T. M. Reyes, K. Lewis, M. H. Perrin et al., "Urocortin II: a member of the corticotropin-releasing factor (CRF) neuropeptide family that is selectively bound by type 2 CRF receptors," Proceedings of the National Academy of Sciences of the United States of America, vol. 98, no. 5, pp. 2843-2848, 2001.

[6] K. Lewis, C. Li, M. H. Perrin et al., "Identification of urocortin III, an additional member of the corticotropin-releasing factor (CRF) family with high affinity for the CRF2 receptor," Proceedings of the National Academy of Sciences of the United States of America, vol. 98, no. 13, pp. 7570-7575, 2001.

[7] P. C. Montecucchi, A. Anastasi, R. de Castiglione, and V. Erspamer, "Isolation and amino acid composition of sauvagine. An active polypeptide from methanol extracts of the skin of the South American frog Phyllomedusa sauvagei," International Journal of Peptide and Protein Research, vol. 16, no. 3, pp. 191-199, 1980.

[8] K. Lederis, W. Vale, and J. Rivier, "Urotensin I-a novel CRFlike peptide in Catostomus commersoni urophysis," Proceedings of the Western Pharmacology Society, vol. 25, pp. 223-227, 1982.

[9] R. Chen, K. A. Lewis, M. H. Perrin, and W. W. Vale, "Expression cloning of a human corticotropin-releasing-factor receptor," Proceedings of the National Academy of Sciences of the United States of America, vol. 90, no. 19, pp. 8967-8971, 1993.

[10] M. Perrin, C. Donaldson, R. Chen et al., "Identification of a second corticotropin-releasing factor receptor gene and characterization of a cDNA expressed in heart," Proceedings of the
National Academy of Sciences of the United States of America, vol. 92, no. 7, pp. 2969-2973, 1995.

[11] G. Telegdy and A. Adamik, "Involvement of CRH receptors in urocortin-induced hyperthermia," Peptides, vol. 29, no. 11, pp. 1937-1942, 2008.

[12] S. C. Weninger, L. L. Peters, and J. A. Majzoub, "Urocortin expression in the Edinger-Westphal nucleus is up-regulated by stress and corticotropin-releasing hormone deficiency," Endocrinology, vol. 141, no. 1, pp. 256-263, 2000.

[13] D. E. Vetter, C. Li, L. Zhao et al., "Urocortin-deficient mice show hearing impairment and increased anxiety-like behavior," Nature Genetics, vol. 31, no. 4, pp. 363-369, 2002.

[14] X. Wang, H. Su, L. D. Copenhagen et al., "Urocortin-deficient mice display normal stress-induced anxiety behavior and autonomic control but an impaired acoustic startle response," Molecular and Cellular Biology, vol. 22, no. 18, pp. 6605-6610, 2002.

[15] A. A. Zalutskaya, M. Arai, G. S. Bounoutas, and A. B. Abou-Samra, "Impaired adaptation to repeated restraint and decreased response to cold in urocortin 1 knockout mice," American Journal of Physiology, Endocrinology and Metabolism, vol. 293, no. 1, pp. E259-E263, 2007.

[16] B. A. de Fanti and J. A. Martínez, "Central urocortin activation of sympathetic-regulated energy metabolism in Wistar rats," Brain Research, vol. 930, no. 1-2, pp. 37-41, 2002.

[17] G. Telegdy, A. Adamik, and G. Tóth, "The action of urocortins on body temperature in rats," Peptides, vol. 27, no. 9, pp. 22892294, 2006.

[18] S. F. Morrison and K. Nakamura, "Central neural pathways for thermoregulation," Frontiers in Bioscience, vol. 16, no. 1, pp. 74104, 2011.

[19] S. Pitoni, H. L. Sinclair, and P. J. D. Andrews, "Aspects of thermoregulation physiology," Current Opinion in Critical Care, vol. 17, no. 2, pp. 115-121, 2011.

[20] T. Kozicz, L. Sterrenburg, and L. Xu, “Does midbrain urocortin 1 matter? A 15-year journey from stress (mal)adaptation to energy metabolism," Stress, vol. 14, no. 4, pp. 376-383, 2011.

[21] M. J. Figueiredo, A. S. C. Fabricio, R. R. Machado, M. C. C. Melo, D. M. Soares, and G. E. P. Souza, "Increase of core temperature induced by corticotropin-releasing factor and urocortin: a comparative study," Regulatory Peptides, vol. 165, no. 2-3, pp. 191-199, 2010.

[22] A. Asakawa, A. Inui, N. Ueno et al., "Urocortin reduces oxygen consumption in lean and ob/ob mice," International journal of molecular medicine, vol. 7, no. 5, pp. 539-541, 2001.

[23] S. C. Heinrichs, D. L. Li, and S. Iyengar, "Corticotropinreleasing factor (CRF) or CRF binding-protein ligand inhibitor administration suppresses food intake in mice and elevates body temperature in rats," Brain Research, vol. 900, no. 2, pp. 177-185, 2001.

[24] K. M. Carlin, W. W. Vale, and T. L. Bale, "Vital functions of corticotropin-releasing factor (CRF) pathways in maintenance and regulation of energy homeostasis," Proceedings of the National Academy of Sciences of the United States of America, vol. 103, no. 9, pp. 3462-3467, 2006.

[25] J. M. Steffen and X. J. Musacchia, "Glucoforticoids and hypothermic induction and survival in the rat," Cryobiology, vol. 22, no. 4, pp. 385-391, 1985.

[26] L. A. Ketzer, A. P. Arruda, D. P. Carvalho, and L. de Meis, "Cardiac sarcoplasmic reticulum $\mathrm{Ca}^{2+}$-ATPase: heat production and phospholamban alterations promoted by cold exposure and 
thyroid hormone," American Journal of Physiology, Heart and circulatory physiology, vol. 297, no. 2, pp. H556-H563, 2009.

[27] V. Golozoubova, E. Hohtola, A. Matthias, A. Jacobsson, B. Cannon, and J. Nedergaard, "Only UCP1 can mediate adaptive nonshivering thermogenesis in the cold," The FASEB Journal, vol. 15, no. 11, pp. 2048-2050, 2001. 

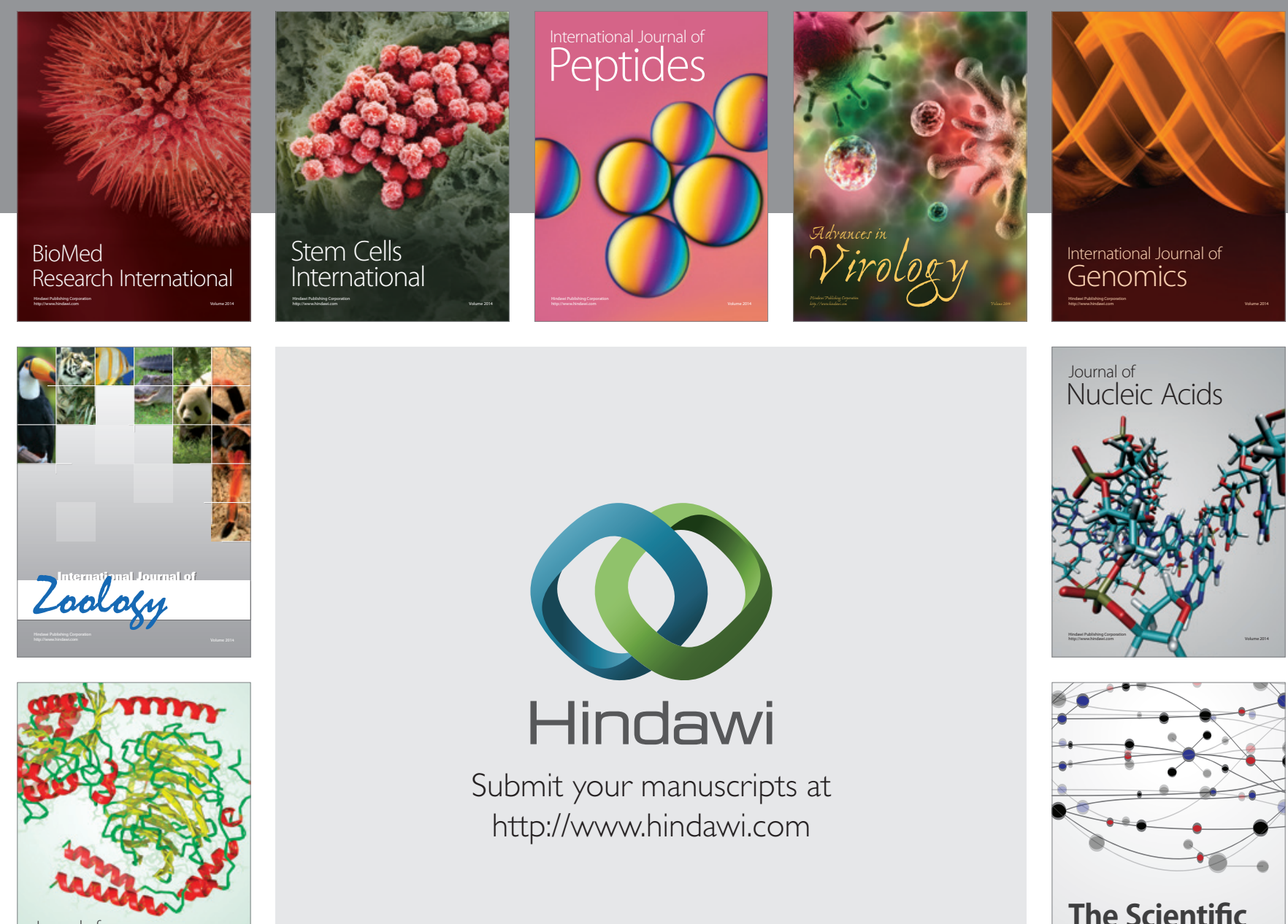

Submit your manuscripts at

http://www.hindawi.com

Journal of
Signal Transduction
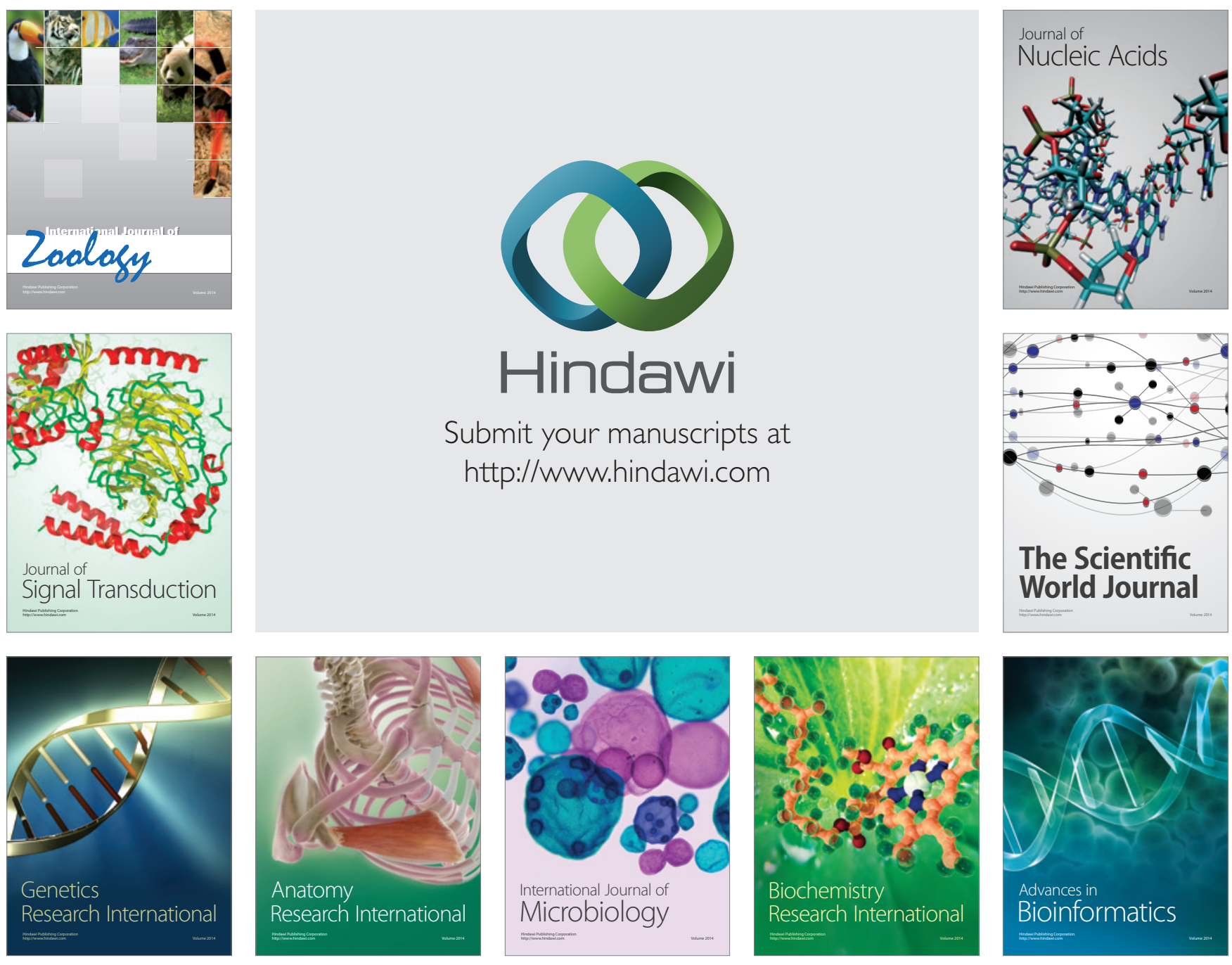

The Scientific World Journal
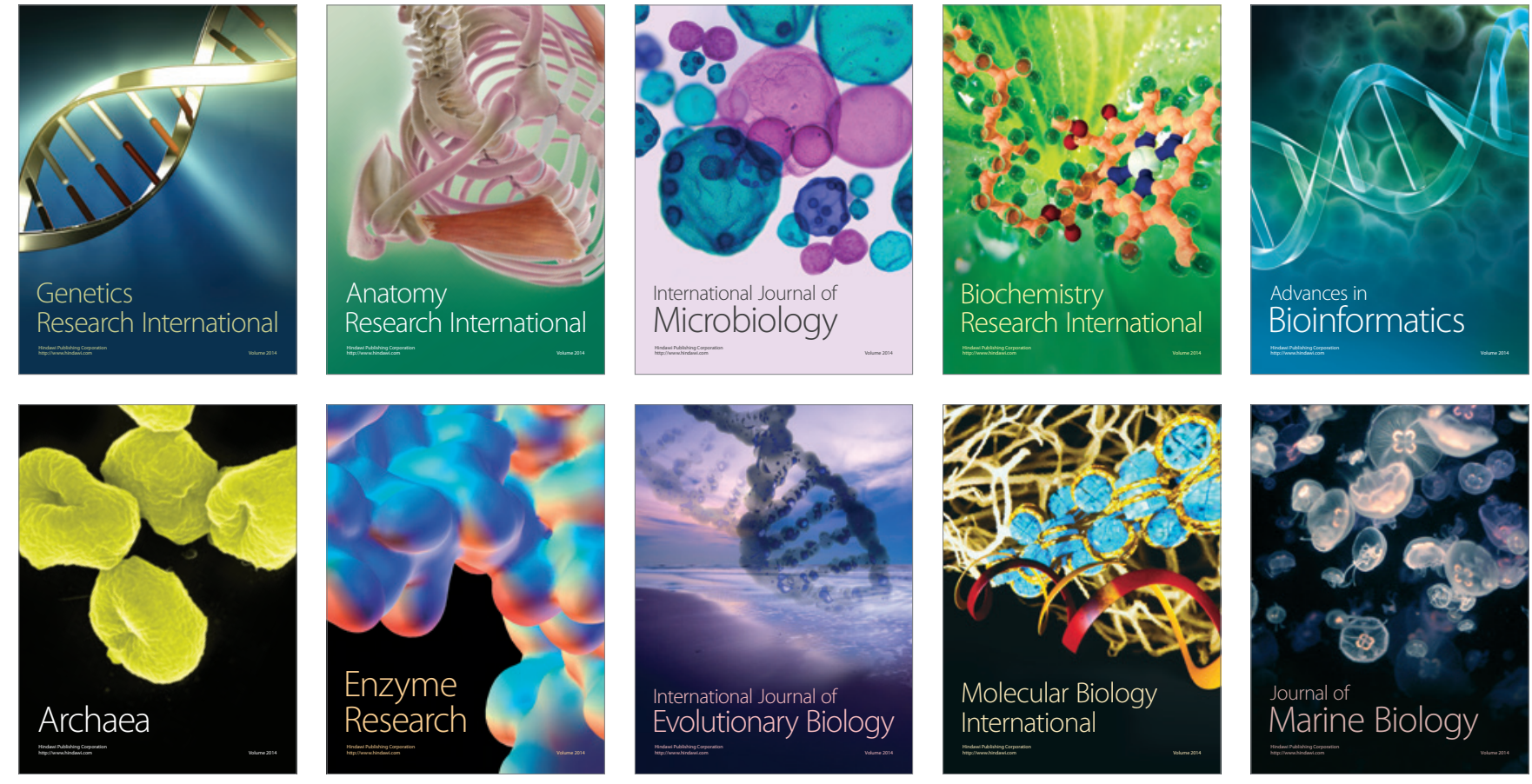